\title{
Association of cardiac biomarkers with acute kidney injury after cardiac surgery: A multicenter cohort study
}

\author{
Emilie P. Belley-Côté, MD, ${ }^{\mathrm{a}}$ Chirag R. Parikh, MD, PhD, ${ }^{\mathrm{b}}$ Colleen R. Shortt, BSc, \\ Steven G. Coca, DO, MS, ${ }^{\mathrm{d}}$ Amit X. Garg, MD, PhD, MA, ${ }^{\mathrm{e}, \mathrm{f}, \mathrm{i}}$ John W. Eikelboom, MD, MBBS, ${ }^{\mathrm{g}, \mathrm{h}}$ \\ Peter Kavsak, PhD, ${ }^{\mathrm{c}}$ Eric McArthur, MSc, ${ }^{1}$ Heather Thiessen-Philbrook, MMath, AStat, ${ }^{\mathrm{b}}$ and \\ Richard P. Whitlock, MD, PhD, ${ }^{a, h, j}$ for the TRIBE-AKI Consortium*
}

\begin{abstract}
Objective: Acute kidney injury is common after cardiac surgery and associated with postoperative mortality. Perioperative cardiac biomarkers may predict acute kidney injury and mortality. We evaluated whether cardiac biomarkers were associated with severe acute kidney injury, defined as a doubling in serum creatinine or requiring renal replacement therapy during hospital stay after surgery, and mortality.
\end{abstract}

Methods: In a prospective multicenter cohort of adults undergoing cardiac surgery, we measured the following biomarkers in preoperative and postoperative banked plasma: high-sensitivity troponin $\mathrm{T}$, cardiac troponin $\mathrm{I}$, creatine kinase-MB, and N-terminal prohormone of brain natriuretic peptide.

Results: In the patients who were discharged alive, severe acute kidney injury occurred in 37 of $960(3.9 \%)$, and 43 of $960(4.5 \%)$ died within 1 year of follow-up. N-terminal prohormone of brain natriuretic peptide was the only preoperative biomarker that was independently associated with severe acute kidney injury (with log transformation, adjusted odds ratio, 1.4; 95\% confidence interval, 1.0-1.9). Biomarkers measured within 6 hours of surgery (day 1) were all associated with severe acute kidney injury. Preoperative N-terminal prohormone of brain natriuretic peptide was also independently associated with 1-year mortality (with $\log$ transformation, adjusted odds ratio, 1.7; 95\% confidence interval, 1.2-2.2). Patients in the highest tertile for $\mathrm{N}$-terminal prohormone of brain natriuretic peptide preoperatively $(>1006.4 \mathrm{ng} / \mathrm{L})$ had marked increases in their risk for 1-year mortality (adjusted odds ratio, 27.2; 95\% confidence interval, 3.5-213.5). Day $1 \mathrm{~N}$-terminal prohormone of brain natriuretic peptide

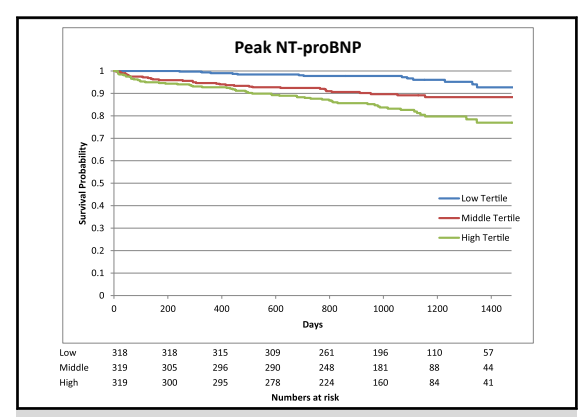

Association between highest measured NT-proBNP tertiles and long-term mortality.

\section{Central Message}

NT-proBNP is the most promising of the biomarkers we studied for the prediction of postoperative severe AKI and mortality.

\section{Perspective}

The integration of biomarkers with preoperative risk prediction tools could refine their predictive value and help patients and clinicians weight the surgical procedure-associated risks and benefits Given the proven benefit to BNP-guided therapy in congestive heart failure, NT-proBNP modulation to prevent postoperative $\mathrm{AKI}$ and mortality warrants further investigation.

See Editorial Commentary page 252.
From the Departments of ${ }^{\mathrm{a} C l i n i c a l}$ Epidemiology and Biostatistics, and ${ }^{\mathrm{c}}$ Pathology and Molecular Medicine, ${ }^{\mathrm{g}}$ Medicine, and ${ }^{\mathrm{j}}$ Surgery, McMaster University; ${ }^{\mathrm{b}}$ Department of Internal Medicine, Yale University School of Medicine and the Clinical Epidemiology Research Center Veterans Affairs Connecticut Healthcare System, West Haven, Conn; ${ }^{\mathrm{d}}$ Department of Internal Medicine, Icahn School of Medicine at Mount Sinai, New York, NY; ${ }^{\mathrm{e}}$ Division of Nephrology, Department of Medicine and ${ }^{\mathrm{f}}$ Department of Epidemiology and Biostatistics, University of Western Ontario, London; ${ }^{\mathrm{h}}$ Population Health Research Institute, Hamilton; and ${ }^{\mathrm{i}}$ Institute for Clinical Evaluative Sciences, Ontario, Canada.

This study was supported by the Institute for Clinical Evaluative Sciences, which is funded by an annual grant from the Ontario Ministry of Health and Long-Term Care. The opinions, results, and conclusions reported in this article are those of the authors and are independent from the funding sources. No endorsement by the Institute for Clinical Evaluative Sciences or the Ontario Ministry of Health and Long-Term Care is intended or should be inferred. The Evidence Investigator Cytokine Custom Array 4 kits were donated by Randox Laboratories Ltd. The granting agency, Randox Laboratories Ltd, did not participate in the design and conduct of the study, collection, management, analysis, and interpretation of the data, and preparation, review, or approval of the manuscript. This study was supported by the National Institutes of Health (NIH) (R01HL085757 to C.R.P.) to fund the TRIBE-AKI Consortium to study novel biomarkers of AKI in cardiac surgery. Biomarker assays were provided in kind by Beckman Coulter and Roche Diagnostics. C.R.P. is supported by the NIH (K24DK090203) and P30 DK079310-07 O'Brien Center Grant. S.G.C. has been supported by an NIH Career Development Award (K23DK080132). C.R.P., S.G.C., and A.X.G. are members of the NIHsponsored Assess, Serial Evaluation, and Subsequent Sequelae in Acute Kidney Injury Consortium (U01DK082185).

* Members of the TRIBE-AKI Consortium are Dr Prasad Devarajan (University of Cincinnati Children's Hospital), Dr Charles Edelstein (University of Colorado), Dr Cary Passik (Danbury Hospital), Dr Madhav Swaminathan and Dr Uptal Patel (Duke University), Dr Michael Zappitelli (Montreal Children's Hospital), and Dr Isabel Butrymowicz (Yale-New Haven Hospital).

Received for publication Feb 28, 2015; revisions received Dec 8, 2015; accepted for publication Feb 13, 2016; available ahead of print April 1, 2016.

Address for reprints: Richard P. Whitlock, MD, PhD, 237 Barton St East, Hamilton, ON L8L 2X2, Canada (E-mail: Richard.Whitlock@phri.ca).

$0022-5223 / \$ 36.00$

Copyright (C) 2016 by The American Association for Thoracic Surgery

http://dx.doi.org/10.1016/j.jtcvs.2016.02.029 


\section{Abbreviations and Acronyms \\ AKI = acute kidney injury \\ $\mathrm{BNP}=$ brain natriuretic peptide \\ CABG = coronary artery bypass grafting \\ $\mathrm{CI}=$ confidence interval \\ $\mathrm{CK}-\mathrm{MB}=$ creatine kinase-MB \\ $\mathrm{cTnI}=$ cardiac troponin I \\ $\mathrm{CV}=$ coefficient of variation \\ hs-cTnT $=$ high-sensitivity troponin $\mathrm{T}$ \\ NT-proBNP $=$ N-terminal prohormone of brain natriuretic peptide \\ OR = odds ratio \\ QC = quality control \\ ROC $=$ receiver operating characteristic \\ TRIBE-AKI $=$ Translational Research Investigating Biomarker Endpoints in AKI}

\section{Scanning this QR code will take you to the appendices and figures for this article.}

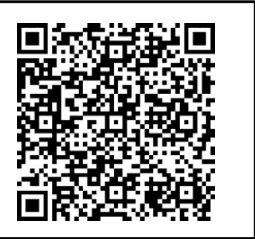

was associated with mortality independently of change in serum creatinine from preoperative baseline.

Conclusions: Of the studied biomarkers, $\mathrm{N}$-terminal prohormone of brain natriuretic peptide was the only preoperative biomarker independently associated with severe acute kidney injury and mortality. Early increases in postoperative cardiac biomarkers were associated with severe acute kidney injury after cardiac surgery. Future research should focus on whether interventions that lower $\mathrm{N}$-terminal prohormone of brain natriuretic peptide can affect postoperative outcomes. (J Thorac Cardiovasc Surg 2016;152:245-51)

Acute kidney injury (AKI) is a frequent complication after cardiac surgery. In the CORONARY trial, when defined as an increase of $50 \%$ or more in baseline serum creatinine, AKI occurred in $21 \%$ of patients undergoing cardiac surgery with cardiopulmonary bypass. ${ }^{1}$ Dialysis is required in $1 \%$ to $2 \%$ of patients undergoing cardiac surgery. 2,3 The development of postoperative AKI is associated with an increased mortality. ${ }^{4,5}$ Preoperative and intraoperative risk factors for AKI have been identified and include age, congestive heart failure, proteinuria, longer cardiopulmonary bypass time, and postoperative low output state. ${ }^{3,5-7}$ Validated pre-operative risk prediction models for dialysis requiring AKI exist. ${ }^{8,9}$ However, less severe AKI also is associated with morbidity and mortality. ${ }^{2,5,6,10-12}$ On an individual patient level, the identification of patients at high risk for AKI could lead to modifications in therapeutic decisions or to a more informed consent before cardiac surgery. For the medical community, it means the possibility of evaluating therapies in a high-risk, high-response population, thereby increasing the chance to identify potentially promising therapies without large trials. Perioperative cardiac biomarkers, such as creatine kinaseMB (CK-MB), cardiac troponin, and N-terminal prohormone of brain natriuretic peptide (NT-proBNP), are associated with an increased mortality risk after cardiac surgery. ${ }^{13-15}$ Higher perioperative NT-proBNP levels have been associated with postoperative AKI, independently of European System for Cardiac Operative Risk Evaluation. ${ }^{16,17}$ With the imminent move toward high-sensitivity cardiac troponin assays, the prognostic value of this biomarker needs to be clarified in patients undergoing cardiac surgery. ${ }^{18}$ In a prospective multicenter cohort of adults undergoing cardiac surgery, we aimed to evaluate whether preoperative and postoperative cardiac biomarkers, including high-sensitivity cardiac troponin $\mathrm{T}$ (hs-cTnT), are associated with the development of severe AKI within the hospital stay and 1-year and long-term mortality after cardiac surgery.

\section{MATERIALS AND METHODS}

\section{Study Design, Setting, and Patient Selection}

Detailed methods of the Translational Research Investigating Biomarker Endpoints in AKI (TRIBE-AKI) cardiac surgery cohort (NCT00774137) have been described. ${ }^{19}$ In summary, after research ethics board approval and informed consent, 1219 patients undergoing cardiac surgery who were at high risk for AKI at 6 academic medical centers in North America were prospectively enrolled between July 2007 and December 2009. The inclusion and exclusion criteria were designed to capture high-risk patients undergoing cardiac surgery to increase the event rates for AKI. High risk for AKI was defined by the presence of 1 or more of the following: emergency surgery, preoperative serum creatinine greater than $2 \mathrm{mg} / \mathrm{dL}(>177 \mu \mathrm{mol} / \mathrm{L})$, ejection fraction $35 \%$ or less or grade 3 or 4 left ventricular dysfunction, age more than 70 years, diabetes mellitus, concomitant $\mathrm{CABG}$ and valve surgery, or repeat revascularization surgery. The evaluation of cardiac biomarkers was a prespecified substudy of the TRIBE-AKI main study. Samples were collected with the a priori defined goal of conducting these analyses.

\section{Clinical and Laboratory Data Collection}

Before surgery, we recorded demographic and patient history data. Information regarding the surgical procedure was obtained from the medical record using the standardized definitions of the Society of Thoracic Surgeons data-collection tool (www.sts.org).

After informed consent, samples were collected preoperatively $(<60$ days before surgery), on day 1 (within 6 hours after surgery), and daily for a maximum of 5 days. The highest measured value was the highest value measured postoperatively. Sample collection was stopped on day 3 in participants who were transferred out of the intensive care unit and did not meet our severe AKI definition. Samples were collected in ethylenediaminetetraacetic acid tubes, centrifuged to separate plasma, and subsequently stored at $-80^{\circ} \mathrm{C}$.

Weobtainedvitalstatusafterdischargethroughvariousmechanismsthatallowed complete follow-up at 1 year. For those living in the United States, we phoned the patients' homes, searched the National Death Index, and reviewed 
hospitalrecords.ForpatientsfromCanada, weusedphonecallsanddataheldat the InstituteforClinicalEvaluativeSciencestoacquirevitalstatus. Thesedatasets were linked using unique, encoded identifiers and analyzed at the Institute for Clinical Evaluative Sciences.

\section{Biomarker Measurements}

After 1 freeze-thaw (storage at $-80^{\circ} \mathrm{C}$ ), biomarker measurements were conducted in batches with an Elecsys 2010 analyzer (Roche, Basel, Switzerland), Roche Diagnostics for NT-proBNP (ng/L) and hs-cTnT (ng/ L), and Beckman Coulter's (Brea, Calif) Access II instrument for cardiac troponin I (cTnI) ( $\mu \mathrm{g} / \mathrm{L}$; AccuTnI assay) and CK-MB ( $\mu \mathrm{g} / \mathrm{L})$. The imprecision of the assays were within the manufacturer's acceptable range and were as follows: NTproBNP inter-assay quality control (QC) level 1 $(\mathrm{n}=148$, mean $=132.8 \mathrm{ng} / \mathrm{L})$ coefficient of variation $(\mathrm{CV})=5 \%$ and level $2(\mathrm{n}=147$, mean $=4423 \mathrm{ng} / \mathrm{L}) \mathrm{CV}=4 \% ; \mathrm{cTnI}$ inter-assay QC level 1 $(\mathrm{n}=165$, mean $=0.04 \mu \mathrm{g} / \mathrm{L}) \mathrm{CV}=22 \%$ and level $3(\mathrm{n}=167$, mean $=3.2 \mu \mathrm{g} / \mathrm{L}) \mathrm{CV}=6 \%$; CK-MB inter-assay QC level $1(\mathrm{n}=164$, mean $=3.8 \mu \mathrm{g} / \mathrm{L}) \mathrm{CV}=6 \%$ and level $3(\mathrm{n}=169$, mean $=69.1 \mu \mathrm{g} / \mathrm{L})$ $\mathrm{CV}=4 \%$; and hs-cTnT inter-assay QC level $1(\mathrm{n}=135$, mean $=25.8 \mathrm{ng} /$ $\mathrm{L}) \mathrm{CV}=10 \%$ and QC level $2(\mathrm{n}=134$, mean $=1993.3 \mathrm{ng} / \mathrm{L}) \mathrm{CV}=3 \%$. Samples were analyzed according to the manufacturer's specifications, and laboratory staff were blinded to clinical outcomes. For NTproBNP, the analyzer automatically calculated the concentration in $\mathrm{pmol} / \mathrm{L}$; however, to be consistent with the literature preference for this analyte (ie, mass units), the results were converted to $\mathrm{ng} / \mathrm{L}$ by the following conversion factor: $\mathrm{pmol} / \mathrm{L} \times 8.457=\mathrm{ng} / \mathrm{L}$. Preoperative and postoperative serum creatinine was measured as part of routine clinical care in hospital laboratories.

\section{Statistical Analysis}

Patient characteristics were compared between groups of patients with and without primary outcomes (severe AKI defined as a doubling in serum creatinine from baseline or requiring renal replacement therapy during hospital stay, and mortality at 1 year and on long-term follow-up) using 2-sample $t$ test or Wilcoxon Mann-Whitney rank-sum test for continuous variables and chi-square test for categoric and binary variables. For each biomarker at each time point, we divided the cohort into tertiles to evaluate the association of each specific biomarker at each specific time point with severe AKI and 1-year mortality. After continuous log-transformation of the biomarkers, logistic regression models were used to determine the unadjusted and adjusted odds ratios (ORs) for severe AKI and 1-year mortality. Cox regression models were used to determine the unadjusted and adjusted hazard ratios for long-term mortality (median follow-up of 3 years). Adjustments were made using covariates that predict severe AKI and mortality: age (per year), sex, white race, cardiopulmonary bypass time greater than 120 minutes, nonelective surgery, preoperative estimated glomerular filtration rate, diabetes, hypertension, center, congestive heart failure, myocardial infarction, preoperative urine albumin to creatinine ratio, and type of surgery (CABG or valve vs all others). ${ }^{5,6,8,9}$ Each time point was handled as an independent event and analyzed separately.

Receiver operating characteristic (ROC) curves were constructed to find the optimal cut-point of the ROC curve (ie, the Youden index) for the prediction of severe AKI and 1-year mortality for each biomarker at each time point. We also identified the cut-points corresponding to the lower value of each tertile range.

We stratified the highest measured biomarker values in tertiles and built Kaplan-Meier curves to visually show the potential association between highest measured biomarker values and long-term mortality.

Statistical analyses were conducted using SAS 9.3 (SAS Institute Inc, Cary, NC). Small cell counts are presented only for data collected by TRIBE-AKI and not from the Institute for Clinical Evaluative Sciences data holdings.

\section{RESULTS}

Between July 2007 and December 2009, 1238 eligible patients undergoing cardiac surgery in participating centers consented to participate. Of those, 239 were excluded because samples were insufficient to measure all cardiac biomarkers on 3 consecutive postoperative days, 19 were excluded for various other reasons, and 20 additional patients were excluded after they died during the index hospital stay (Figure 1). Of the 960 patients included in our analyses, 37 (3.9\%) developed severe AKI, 43 (4.5\%) died at 1 year, and $104(10.8 \%)$ died on long-term followup (Table 1 and Appendix E1). AKI occurred after a median of 3 days (interquartile range, 2-4) after surgery.

Patients who developed severe AKI were more likely to have a history of hypertension and congestive heart failure. They had longer cardiopulmonary bypass and crossclamp times. Congestive heart failure and postoperative severe AKI were significantly more common in patients who died at 1 year.

Nine patients $(0.9 \%)$ required acute dialysis (Table 2 and Appendix E2). Nonrenal complications occurred more frequently in the patients who developed severe AKI. Mechanical ventilation duration and intensive care unit and hospital stay were longer for the patients with severe AKI and those who died at 1 year and on long-term follow-up.

Both highest measured hs-cTnT and cTnI were on day 2 (Appendix E3), whereas highest measured CK-MB was on day 1 and highest NT-pro-BNP was on day 3 (Appendix E3). All postoperative biomarkers were higher in the group that developed severe AKI.

\section{Severe Acute Kidney Injury}

Associations of continuous log-transformed values of biomarkers at different time perioperative points with severe AKI are presented in Table 3. NT-proBNP was the only preoperative biomarker associated with severe AKI and remained statistically significant after adjustment for age, sex, white race, nonelective surgery, diabetes, hypertension, center, congestive heart failure, myocardial infarction, preoperative urine albumin to creatinine ratio, cardiopulmonary bypass time greater than 120 minutes, preoperative estimated glomerular filtration rate, and type of surgery. Patients in the highest tertile preoperatively (NT-proBNP $\geq 1009.7 \mathrm{ng} / \mathrm{L}$ ) had a more than 4-fold increase in severe AKI (adjusted OR, $4.5 ; 95 \%$ confidence interval $[\mathrm{CI}], 1.3-15.1 ; P=.02)$. First postoperative biomarkers (measured within 6 hours of surgery) including NT-proBNP, hs-cTnT, cTnI, and CK-MB were all associated with severe AKI on both univariable and multivariable analyses. On day 1, patients in the third tertile of NT-proBNP ( $\geq 828.8 \mathrm{ng} / \mathrm{L})$ and hs-cTnT $(\geq 591.4 \mathrm{ng} / \mathrm{L})$ had the highest increase in risk of severe AKI (adjusted OR, 4.0; 95\% CI, 1.2-13.4; $P=.02$ and adjusted OR, 4.6; 95\% CI, 1.5-14.4; $P<.01$, respectively) (Appendix E4). The highest measured concentrations of these biomarkers also were associated with severe AKI. However, the highest measured concentration occurred concurrently with the occurrence of AKI. Despite their association with 


\section{Patient Flow Diagram}

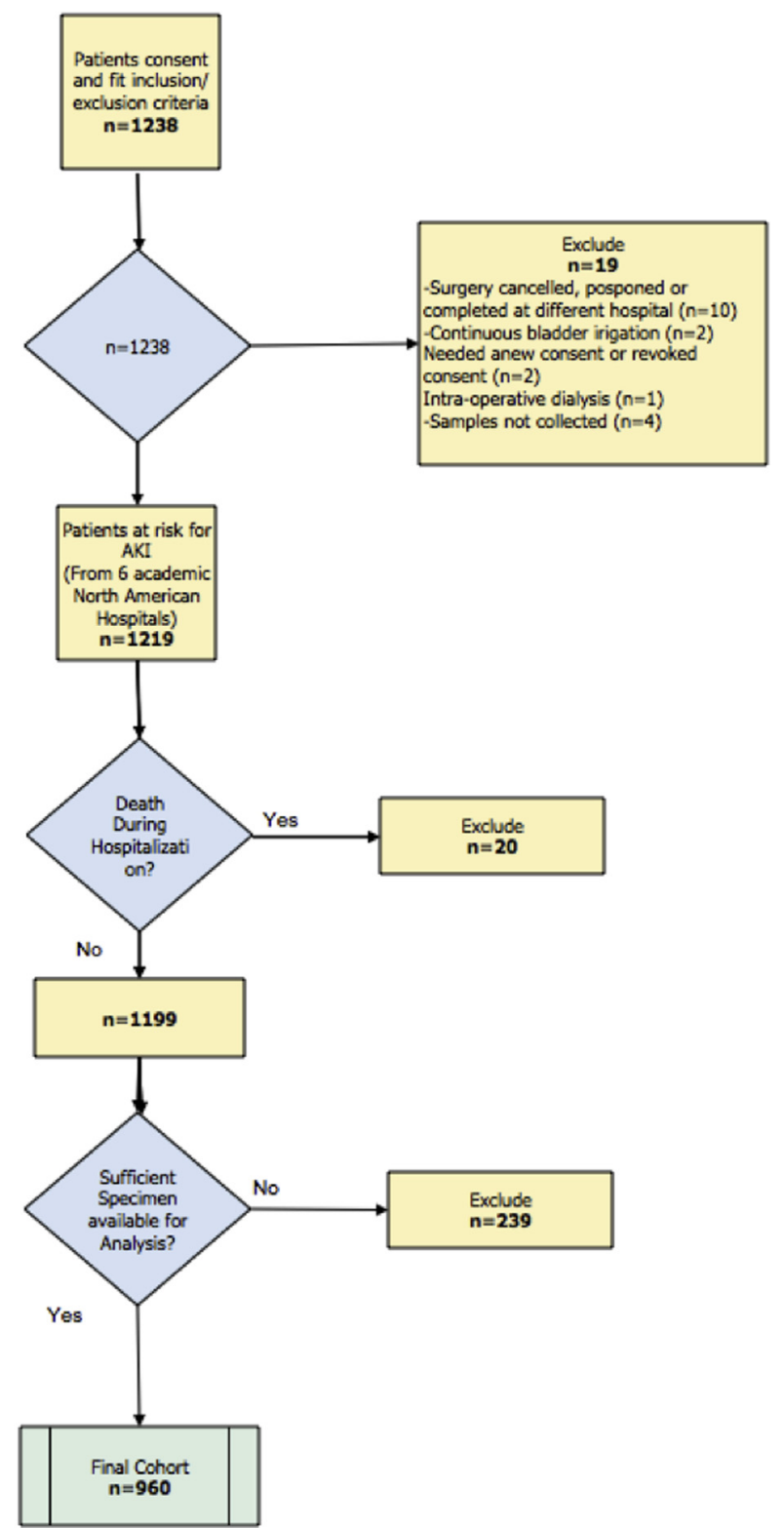

FIGURE 1. Study flow diagram. $A K I$, Acute kidney injury.

severe AKI, the discriminatory properties of the cardiac biomarkers, as assessed by ROC curve analyses, were modest (Appendix E5).

\section{One-Year Mortality}

Table 4 shows the association between the biomarkers and the 1-year mortality. Preoperative NT-proBNP and hscTnT were associated with 1-year mortality and remained significant after adjustment for age, sex, white race, nonelective surgery, diabetes, hypertension, center, congestive heart failure, myocardial infarction, preoperative urine albumin to creatinine ratio, and type of surgery. Patients in the highest tertile for NT-proBNP (range: $>1009.8 \mathrm{ng} / \mathrm{L}$ ) and hs-cTnT (range: $>19.4 \mathrm{ng} / \mathrm{L}$ ) preoperatively had marked increases in their risk for 1-year mortality (adjusted OR, 27.2; 95\% CI, 3.5-213.5; $P<.01$ and adjusted OR, 4.2; $95 \%$ CI, $1.3-13.7 ; P=.02$, respectively). Day 1 hs-cTnT and cTnI were associated with mortality univariately but not after adjustment for patient characteristics, surgical factors, and change in serum creatinine day 1 from baseline. Day 1 NT-proBNP was associated with 1-year mortality independently of clinical characteristics and change in serum creatinine from preoperative level. The risk increased with higher NT-proBNP concentrations (Appendix E6): The adjusted OR was 15.1 (95\% CI, 1.9-117.9; $P<.01)$ in the second tertile $(265.6-827.9 \mathrm{ng} / \mathrm{L})$ and $25.7(95 \%$ CI, 3.3-201.2; $P<.01)$ in the third tertile $(\geq 828.8 \mathrm{ng} / \mathrm{L})$. Highest measured hs-cTnT and cTnI were not associated with 1-year mortality after adjustment, whereas highest measured NT-proBNP remained significantly associated with mortality. Highest measured hs-cTnT and NTproBNP have similar area under the curves for predicting 1-year mortality (Appendix E7).

\section{Long-Term Mortality}

The median follow-up of the cohort was 3 years (2.23.5 years). The association between log-transformed biomarkers and long-term mortality is shown in Appendix E8. Preoperative hs-cTnT, CK-MB, and NT-proBNP were associated with long-term mortality after multivariable analysis. After surgery, no association between mortality and CK-MB was observed. Day 1 and highest measured values of hs-cTnT and NT-pro-BNP were associated with long-term mortality. For NT-proBNP, the risk increased with higher values at all time points. Kaplan-Meier curves showing the association between highest measured biomarkers divided in tertiles and long-term mortality are presented in Appendix E9.

\section{DISCUSSION \\ Key Results}

NT-proBNP seems to be the most promising of the studied cardiac biomarkers. Higher preoperative and day 1 postoperative concentrations of NT-proBNP were associated with an increased risk for severe AKI. Mortality at 1 year and on long-term follow-up was associated with NT-proBNP concentrations at all time points and was independent of increases in serum creatinine after cardiac surgery. All cardiac biomarkers on day 1 were associated with severe AKI. Preoperative and highest measured hs-cTnT concentrations were associated with 1-year mortality, although after multivariable adjustment only the preoperative concentration was significant. However, hs-cTnT levels at all time points were independently associated with long-term mortality. cTnI was not 
TABLE 1. Baseline patient characteristics by severe acute kidney injury

\begin{tabular}{|c|c|c|c|}
\hline Characteristics & $\begin{array}{l}\text { Severe } \\
\text { AKI }\end{array}$ & $\begin{array}{c}\text { No severe } \\
\text { AKI }\end{array}$ & $P$ value \\
\hline $\mathrm{N}(\%)$ & $37(3.9)$ & $923(96.1)$ & \\
\hline Age (y) mean (SD) & $70.7(10.4)$ & $71.53(10)$ & 6 \\
\hline Male, n (\%) & $27(73)$ & $628(68)$ & .5 \\
\hline White, n (\%) & $33(89.2)$ & 864 (93.6) & .3 \\
\hline \multicolumn{4}{|l|}{ History, n (\%) } \\
\hline Diabetes & $16(43.2)$ & $363(39.3)$ & .6 \\
\hline Hypertension & $34(91.9)$ & 725 (78.5) & .05 \\
\hline Congestive heart failure & $15(40.5)$ & $215(23.3)$ & .02 \\
\hline $\mathrm{LVEF}<40 \%$ & $3(8.1)$ & $95(10.3)$ & .7 \\
\hline \multicolumn{4}{|l|}{ eGFR, n (\%) } \\
\hline$>60 \mathrm{~mL} / \mathrm{min} / 1.73 \mathrm{~m}^{2}$ & $22(59.5)$ & $611(66.2)$ & .2 \\
\hline $30-60 \mathrm{~mL} / \mathrm{min} / 1.73 \mathrm{~m}^{2}$ & $12(32.4)$ & $284(30.8)$ & \\
\hline$<30 \mathrm{~mL} / \mathrm{min} / 1.73 \mathrm{~m}^{2}$ & $3(8.1)$ & $28(3)$ & \\
\hline \multicolumn{4}{|l|}{ Urine albumin/creatinine, $\mathrm{n}(\%)$} \\
\hline$<10$ & $10(27)$ & $326(35.3)$ & .8 \\
\hline $10-30$ & $12(32.4)$ & $273(29.6)$ & \\
\hline $30-300$ & $12(32.4)$ & 255 (27.6) & \\
\hline$>300$ & $3(8.1)$ & $58(6.3)$ & \\
\hline Nonelective surgery, n (\%) & $10(27)$ & 177 (19.2) & .2 \\
\hline \multicolumn{4}{|l|}{ Surgery, n (\%) } \\
\hline Isolated CABG or valve & $28(75.7)$ & 724 (78.4) & .7 \\
\hline $\mathrm{CABG}+$ valve & $9(24.3)$ & 199 (21.6) & .9 \\
\hline Off-pump surgery, n (\%) & $4(10.8)$ & $83(9.0)$ & .9 \\
\hline Re-do surgery, n (\%) & $1(2.7)$ & $17(1.8)$ & .5 \\
\hline CPB time (min), mean (SD) & $177(101)$ & $110(55)$ & $<.001$ \\
\hline $\begin{array}{l}\text { Crossclamp time }(\mathrm{min}), \\
\text { mean }(\mathrm{SD})\end{array}$ & $121(67)$ & $75(42)$ & $<.001$ \\
\hline
\end{tabular}

$\overline{A K I}$, Acute kidney injury; $S D$, standard deviation; $L V E F$, left ventricular ejection fraction; $e G F R$, estimated glomerular filtration rate; $C A B G$, coronary artery bypass grafting; $C P B$, cardiopulmonary bypass.

associated with 1-year and long-term mortality. CK-MB was not associated with 1-year mortality, but the preoperative level was associated with long-term mortality.

\section{Existing Studies}

NT-proBNP is thought to be a predictor of complications after cardiac surgery. A systematic review published in 2012 evaluated the role of preoperative brain natriuretic peptide (BNP) and NT-proBNP in predicting mortality (4 studies, 1101 patients). The summary area under the curve was 0.61 (95\% CI, 0.51-0.70), suggesting a moderate association. $^{13}$ In another observational study of 365 intermediate-risk patients undergoing CABG surgery, preoperative NT-proBNP was associated with morbidity (including renal failure) and mortality. ${ }^{16} \mathrm{~A}$ prospective cohort including 1559 patients undergoing on-pump cardiac surgery reported that a postoperative (day 1 and 2) BNP value greater than $790 \mathrm{ng} / \mathrm{L}$ was associated with an adjusted hazard ratio for mortality of 2.44 (95\% CI, 1.65-3.62). ${ }^{17} \mathrm{In}$ that study, postoperative BNP had additional predictive value for 1-year mortality when combined with the logistic
TABLE 2. Postoperative complications during hospitalization for cardiac surgery by severe acute kidney injury

\begin{tabular}{|c|c|c|c|}
\hline Complications & Severe AKI & No severe AKI & $P$ value \\
\hline \multicolumn{4}{|l|}{ Clinical AKI, n (\%) } \\
\hline $\begin{array}{c}\text { Increase }>50 \% \text { or } \\
>0.3 \mathrm{mg} / \mathrm{dL}\end{array}$ & $37(100.0)$ & $293(31.7)$ & $<.001$ \\
\hline Acute dialysis & $9(24.3)$ & $0(0.0)$ & $<.001$ \\
\hline \multicolumn{4}{|c|}{ Nonrenal complications, n (\%) } \\
\hline None & $19(51.4)$ & $572(62.0)$ & $<.001$ \\
\hline 1 or 2 & $6(16.2)$ & $283(30.7)$ & \\
\hline$>2$ & $12(32.4)$ & $68(7.4)$ & \\
\hline $\begin{array}{l}\text { Oliguria on postoperative } \\
\text { day } 1, \mathrm{n}(\%)\end{array}$ & $0(0.0)$ & $11(1.2)$ & .6 \\
\hline $\begin{array}{l}\text { Mechanical ventilation } \\
\quad>48 \mathrm{~h}, \mathrm{n}(\%)\end{array}$ & $15(40.5)$ & $19(2.1)$ & $<.001$ \\
\hline $\begin{array}{l}\text { ICU length of stay }(\mathrm{d}), \\
\text { median (IQR) }\end{array}$ & $5(3-17)$ & $2(1-3)$ & $<.001$ \\
\hline $\begin{array}{l}\text { Hospital length of stay }(\mathrm{d}), \\
\text { median (IQR) }\end{array}$ & $17(8-27)$ & $6(5-8)$ & $<.001$ \\
\hline
\end{tabular}

European System for Cardiac Operative Risk Evaluation. ${ }^{17}$ In another study that included only patients undergoing valvular surgery, preoperative BNP levels were found to be predictive of postoperative inotrope duration (OR, 5.9; 95\% CI, 1.2-29.68) and ventilation time (OR, 4.7; 95\% CI, 1.74-17.21). ${ }^{20}$ BNP and NT-proBNP levels reflect cardiac filling pressures. ${ }^{21}$ Therefore, these biomarkers provide a surrogate for hemodynamic status, which explains their association with severe AKI and mortality after cardiac surgery. Our results confirm the results of previous smaller studies. However, we have the advantage of a larger sample size that enables adjustment for more variables and greater generalizability. Moreover, the simultaneous measurement of CK-MB, cTnI, hs-cTnT, and NT-proBNP allows head-to-head comparisons between these biomarkers.

The type of procedure performed and the crossclamp time affect postoperative CK-MB and cTnI release, ${ }^{22}$ and both have been shown to predict both AKI and 1-year mortality. ${ }^{5}$ Therefore, the association of day 1 biomarkers with severe AKI does not come as a surprise. However, the absence of association between the widely used biomarkers (CK-MB and cTnI) and mortality warrants further discussion. Arbitrarily, a cardiac biomarker value more than 10 times the upper limit of normal is used in the Third Universal definition of myocardial infarction for patients who have undergone CABG surgery. ${ }^{23}$ A clinically relevant postcardiac surgery myocardial infarction definition should be associated with increased mortality and morbidity. It is of concern that the biomarkers that are currently available in most centers failed to predict 1-year and long-term mortality. The exclusion of patients with very early mortality and the adjustment for other known risk factors might explain this unexpected finding. The 
TABLE 3. Log-transformed biomarkers and association with severe acute kidney injury

\begin{tabular}{|c|c|c|c|c|c|c|}
\hline & Time point & $\mathbf{n}$ & Unadjusted OR $(95 \%$ CI) & $P$ value & Adjusted OR* $(95 \%$ CI $)$ & $P$ value \\
\hline \multirow[t]{2}{*}{ hs-cTnT } & Preoperative & 928 & $1.11(0.88-1.40)$ & .3671 & $1.17(0.84-1.61)$ & .4 \\
\hline & Day 1 & 949 & $1.96(1.40-2.75)$ & $<.0001$ & $2.10(1.32-3.34)$ & .002 \\
\hline \multirow[t]{2}{*}{$\mathrm{cTnI}$} & Preoperative & 956 & $1.10(0.88-1.37)$ & .4185 & $1.22(0.92-1.63)$ & .2 \\
\hline & Day 1 & 959 & $1.56(1.20-2.02)$ & .0009 & $1.59(1.10-2.28)$ & $<.0001$ \\
\hline \multirow[t]{2}{*}{ CK-MB } & Preoperative & 958 & $1.44(0.95-2.19)$ & .0862 & $1.55(0.94-2.58)$ & .1 \\
\hline & Day 1 & 959 & $2.09(1.42-3.06)$ & .0002 & $2.19(1.31-3.66)$ & .003 \\
\hline \multirow[t]{2}{*}{ NT-proBNP } & Preoperative & 931 & $1.37(1.08-1.74)$ & .0113 & $1.39(1.03-1.88)$ & .03 \\
\hline & Day 1 & 947 & $1.54(1.19-2.00)$ & .0009 & $1.46(1.05-2.03)$ & .02 \\
\hline
\end{tabular}

Day 1 samples were collected within 6 hours of surgery. $O R$, Odds ratio; $C I$, confidence interval; $h s$ - $c$ TnT, high-sensitivity cardiac troponin T; $c T n I$, cardiac troponin I; $C K$ - $M B$, creatine kinase-MB; NT-proBNP, N-terminal prohormone of brain natriuretic peptide. *Adjusted for age, sex, white race, cardiopulmonary bypass time $>120$ minutes, nonelective surgery, preoperative estimated glomerular filtration rate, diabetes, hypertension, center, congestive heart failure, myocardial infarction, preoperative urine albumin to creatinine ratio, and type of surgery.

inclusion of patients who underwent isolated valvular or aortic procedures also could be the cause. A recent study of patients who underwent isolated valvular surgery found no association between CK-MB and cTnI and short-term morbidity. $^{20}$

Clinicians often use high-sensitivity cardiac troponin assays interchangeably with sensitive cardiac troponin assays. However, these biomarkers behaved differently in our study. Preoperative hs-cTnT was associated with 1 -year and long-term mortality, whereas cTnI was not. The increased analytic sensitivity of these assays accounts for their capacity to identify high-risk patients, and their predictive value in cardiac surgery mirrors what was seen in other nonacute coronary syndrome populations. ${ }^{21-25}$ Of note, the cut-point for highest measured hs-cTnT identified on our ROC curve for 1-year mortality was approximately 40 times the upper limit of normal (ie, $40 \times 99$ th percentile), suggesting the currently used myocardial infarction definition $(10 \times 99$ th percentile $)$ may fail to identify patients at higher mortality risk. The transition toward hs-cTn assays means that understanding their perioperative predictive value is crucial. The Vascular events In Surgery patIents cOhort evaluatioN Cardiac Surgery Study
(NCT01842568), a 15,000-patient cohort that is currently recruiting, will inform on the predictors of complications after cardiac surgery, including hs-cTn.

\section{Study Strengths and Limitations}

The included patients were representative of a high-risk North American cardiac surgery population. We minimized the variation in biomarker measurement by centralizing the analyses. This study is the largest prospective cohort evaluating the association of multiple preoperative and postoperative cardiac biomarkers with severe AKI and mortality in cardiac surgery. However, despite including high-risk patients, relatively few events occurred and our model might be over-fitted. The exclusion of patients needing emergency surgery may have contributed to the low event rate. It would be interesting to evaluate the association of cardiac biomarkers with other cardiovascular events to increase the power and number of possible analyses. Moreover, patients may see stroke and myocardial infarction, given the associated morbidity, as being more important than a doubling in serum creatinine. Combining a doubling in serum creatinine with the need for acute dialysis may be questioned but aimed to use the RIFLE criteria for injury

TABLE 4. Log-transformed biomarkers as predictors of 1-year mortality

\begin{tabular}{|c|c|c|c|c|c|c|}
\hline & Time point & $\mathbf{n}$ & OR $(95 \%$ CI $)$ & $P$ value & $\mathbf{O R} *(95 \%$ CI $)$ & $P$ value \\
\hline \multirow[t]{3}{*}{ hs-cTnT } & Preoperative & 928 & $1.30(1.08-1.58)$ & .0065 & & \\
\hline & Day 1 & 949 & $1.45(1.05-2.01)$ & .023 & $1.38(0.90-2.12)$ & .1 \\
\hline & Highest measured & 952 & $1.64(1.18-2.28)$ & .0035 & $1.50(0.98-2.29)$ & .1 \\
\hline \multirow[t]{3}{*}{ cTnI } & Preoperative & 956 & $1.16(0.96-1.41)$ & .1285 & & \\
\hline & Day 1 & 959 & $1.30(1.02-1.67)$ & .0353 & $1.25(0.89-1.74)$ & .2 \\
\hline & Highest measured & 959 & $1.43(1.11-1.85)$ & .006 & $1.29(0.93-1.79)$ & .1 \\
\hline \multirow[t]{3}{*}{ CK-MB } & Preoperative & 958 & $0.92(0.58-1.47)$ & .7305 & & \\
\hline & Day 1 & 959 & $1.24(0.87-1.78)$ & .2405 & $1.11(0.71-1.75)$ & .7 \\
\hline & Highest measured & 959 & $1.19(0.82-1.73)$ & .3499 & $1.01(0.64-1.59)$ & 1 \\
\hline \multirow[t]{3}{*}{ NT-proBNP } & Preoperative & 931 & $1.70(1.35-2.14)$ & $<.0001$ & & \\
\hline & Day 1 & 947 & $1.68(1.32-2.14)$ & $<.0001$ & $1.65(1.21-2.23)$ & .001 \\
\hline & Highest measured & 956 & $1.99(1.37-2.88)$ & .0003 & $1.99(1.22-3.26)$ & .006 \\
\hline
\end{tabular}

OR, Odds ratio; $C I$, confidence interval; $h s$ - $c T n T$, high-sensitivity cardiac troponin T; $c T n I$, cardiac troponin I; $C K-M B$, creatine kinase-MB; $N T$-proBNP, N-terminal prohormone of brain natriuretic peptide. *Adjusted for age, sex, white race, cardiopulmonary bypass time $>120$ minutes, nonelective surgery, preoperative estimated glomerular filtration rate, diabetes, hypertension, center, congestive heart failure, myocardial infarction, preoperative urine albumin, and change in creatinine from baseline. 
while accounting for patients needing temporary renal replacement therapy. ${ }^{24}$ The association of cardiac biomarkers with in-hospital mortality, probably the highest risk group, also warrants further research.

\section{Future Directions}

The integration of biomarkers with preoperative risk prediction tools could refine their predictive value and help patients and clinicians weight the surgical procedure-associated risks and benefits. Given the proven benefit to BNP-guided therapy in congestive heart failure, ${ }^{25,26}$ NT-proBNP modulation to prevent postoperative AKI and mortality warrants further investigation.

\section{CONCLUSIONS}

NT-proBNP is the most promising of the biomarkers we studied for the prediction of postoperative severe AKI and mortality. The commonly used CK-MB and cTnI did not seem to provide prognostic information in addition to clinical characteristics, whereas preoperative hs-cTn did have prognostic utility for mortality beyond such parameters. Widespread update of hs-cTn should help physicians better inform patients and their families of risk.

\section{Conflict of Interest Statement}

C.R.P. is a consultant for Cardiorentis and AbbVie, and a scientific advisor for Thrasos. A.X.G. has received research funding from Astellas, Roche, Fresenius, Ortho-Biotech, and Pfizer Canada. J.W.E. reports grants and personal fees from Bayer, Boehringer-Ingelheim, AstraZeneca, Bristol-Myers Squibb, GlaxoSmithKline, Pfizer, Janssen, and Sanofi-Aventis, and personal fees from Daiichi Sankyo and Eli Lilly. P.K. has obtained grants/honorarium/advisory or consultant fees from $\mathrm{Ab}$ bott Laboratories, Abbott Point of Care, Beckman Coulter, Ortho Clinical Diagnostics, Roche Diagnostics, and the Canadian Agency for Drugs and Technologies in Health. All other authors have nothing to disclose with regard to commercial support.

\section{References}

1. Garg AX, Devereaux PJ, Yusuf S, Cuerden MS, Parikh CR, Coca SG, et al. Kidney function after off-pump or on-pump coronary artery bypass graft surgery: a randomized clinical trial. JAMA. 2014;311:2191-8.

2. Rosner MH, Okusa MD. Acute kidney injury associated with cardiac surgery. Clin J Am Soc Nephrol. 2006;1:19-32.

3. Ostermann ME, Taube D, Morgan CJ, Evans TW. Acute renal failure following cardiopulmonary bypass: a changing picture. Intensive Care Med. 2000;26: $565-71$.

4. Conlon PJ, Stafford-Smith M, White WD, Newman MF, King S, Winn MP, et al. Acute renal failure following cardiac surgery. Nephrol Dial Transplant. 1999;14: 1158-62.

5. Mangano CM, Diamondstone LS, Ramsay JG, Aggarwal A, Herskowitz A, Mangano DT. Renal dysfunction after myocardial revascularization: risk factors, adverse outcomes, and hospital resource utilization. The Multicenter Study of Perioperative Ischemia Research Group. Ann Intern Med. 1998;128:194-203.

6. Chertow GM, Levy EM, Hammermeister KE, Grover F, Daley J. Independent association between acute renal failure and mortality following cardiac surgery. Am J Med. 1998;104:343-8.
7. Li SY, Chuang CL, Yang WC, Lin SJ. Proteinuria predicts postcardiotomy acute kidney injury in patients with preserved glomerular filtration rate. J Thorac Cardiovasc Surg. 2015;149:894-9.

8. Fortescue EB, Bates DW, Chertow GM. Predicting acute renal failure after coronary bypass surgery: cross-validation of two risk-stratification algorithms. Kidney Int. 2000;57:2594-602.

9. Thakar CV, Arrigain S, Worley S, Yared JP, Paganini EP. A clinical score to predict acute renal failure after cardiac surgery. J Am Soc Nephrol. 2005;16: 162-8.

10. Lopez-Delgado JC, Esteve F, Torrado H, Rodriguez-Castro D, Carrio ML, Farrero E, et al. Influence of acute kidney injury on short- and long-term outcomes in patients undergoing cardiac surgery: risk factors and prognostic value of a modified RIFLE classification. Crit Care. 2013;17:R293.

11. Ng SY, Sanagou M, Wolfe R, Cochrane A, Smith JA, Reid CM. Prediction of acute kidney injury within 30 days of cardiac surgery. J Thorac Cardiovasc Surg. 2014;147:1875-83. 1883.e1.

12. Pacini D, Pantaleo A, Di Marco L, Leone A, Barberio G, Parolari A, et al. Risk factors for acute kidney injury after surgery of the thoracic aorta using antegrade selective cerebral perfusion and moderate hypothermia. J Thorac Cardiovasc Surg. 2015;150:127-33.e1.

13. Litton E, Ho KM. The use of pre-operative brain natriuretic peptides as a predictor of adverse outcomes after cardiac surgery: a systematic review and meta-analysis. Eur J Cardiothorac Surg. 2012;41:525-34.

14. Lurati Buse GA, Koller MT, Grapow M, Bolliger D, Seeberger M, Filipovic M The prognostic value of troponin release after adult cardiac surgery - a meta-analysis. Eur J Cardiothorac Surg. 2010;37:399-406.

15. Domanski MJ, Mahaffey K, Hasselblad V, Brener SJ, Smith PK, Hillis G, et al Association of myocardial enzyme elevation and survival following coronary artery bypass graft surgery. JAMA. 2011;305:585-91.

16. Holm J, Vidlund M, Vanky F, Friberg O, Hakanson E, Walther S, et al. EuroSCORE II and N-terminal pro-B-type natriuretic peptide for risk evaluation: an observational longitudinal study in patients undergoing coronary artery bypass graft surgery. Br J Anaesth. 2014;113:75-82.

17. Lurati Buse GA, Bolliger D, Seeberger E, Kasper J, Grapow M, Koller MT, et al Troponin T and B-type natriuretic peptide after on-pump cardiac surgery: prognostic impact on 12-month mortality and major cardiac events after adjustment for postoperative complications. Circulation. 2014;130:948-57.

18. Kavsak PA, Jaffe AS, Hickman PE, Mills NL, Humphries KH, McRae A, et al Canadian Institutes of Health Research dissemination grant on high-sensitivity cardiac troponin. Clin Biochem. 2014;47:155-7.

19. Parikh CR, Coca SG, Thiessen-Philbrook H, Shlipak MG, Koyner JL, Wang Z et al. Postoperative biomarkers predict acute kidney injury and poor outcomes after adult cardiac surgery. J Am Soc Nephrol. 2011;22:1748-57.

20. Singh S, Kapoor A, Agarwal SK, Pande S, Sinha A, Rai H. Differential release kinetics of cardiac biomarkers in patients undergoing valve replacement surgery. J Card Surg. 2014;29:134-40.

21. Iwanaga Y, Nishi I, Furuichi S, Noguchi T, Sase K, Kihara Y, et al. B-type natriuretic peptide strongly reflects diastolic wall stress in patients with chronic heart failure: comparison between systolic and diastolic heart failure. J Am Coll Cardiol. 2006;47:742-8.

22. Mastro F, Guida P, Scrascia G, Rotunno C, Amorese L, Carrozzo A, et al Cardiac troponin I and creatine kinase-MB release after different cardiac surgeries. J Cardiovasc Med (Hagerstown). 2015;16:456-64.

23. Thygesen K, Alpert JS, Jaffe AS, Simoons ML, Chaitman BR, White HD, et al Third universal definition of myocardial infarction. Eur Heart J. 2012;33: 2551-67.

24. Bellomo R, Ronco C, Kellum JA, Mehta RL, Palevsky P, Acute Dialysis Quality Initiative workgroup. Acute renal failure - definition, outcome measures, animal models, fluid therapy and information technology needs: the Second International Consensus Conference of the Acute Dialysis Quality Initiative (ADQI) Group. Crit Care. 2004;8:R204-12.

25. Jourdain P, Jondeau G, Funck F, Gueffet P, Le Helloco A, Donal E, et al Plasma brain natriuretic peptide-guided therapy to improve outcome in heart failure: the STARS-BNP Multicenter Study. J Am Coll Cardiol. 2007;49: 1733-9.

26. Troughton RW, Frampton CM, Yandle TG, Espine EA, Nicholls MG Richards AM. Treatment of heart failure guided by plasma aminoterminal brain natriuretic peptide (N-BNP) concentrations. Lancet. 2000;355:1126-30.

Key Words: acute kidney injury, biomarkers, brain natriuretic peptide, cardiac surgery, mortality, troponin 
APPENDIX E1. Baseline patient characteristics by 1-year mortality

\begin{tabular}{|c|c|c|c|}
\hline Characteristics & Dead at $1 \mathrm{y}$ & Alive at $1 \mathrm{y}$ & $P$ value \\
\hline $\mathrm{N}(\%)$ & $43(4.5)$ & 917 (95.5) & \\
\hline Age $(y)$ mean $(\mathrm{SD})$ & $74(10)$ & $71(10)$ & .1 \\
\hline Male, n (\%) & $29(67.4)$ & $626(68.3)$ & .9 \\
\hline White, n (\%) & $39(90.7)$ & 858 (93.6) & .5 \\
\hline \multicolumn{4}{|l|}{ History, n (\%) } \\
\hline Diabetes & $20(46.5)$ & $359(39.1)$ & .3 \\
\hline Hypertension & $36(83.7)$ & $723(78.8)$ & .4 \\
\hline Congestive heart failure & $18(41.9)$ & $212(23.1)$ & .005 \\
\hline LVEF $<40 \%$ & $5(11.6)$ & $93(10.1)$ & .8 \\
\hline \multicolumn{4}{|l|}{ eGFR, n (\%) } \\
\hline$>60 \mathrm{~mL} / \mathrm{min} / 1.73 \mathrm{~m}^{2}$ & $25(58.1)$ & $608(66.3)$ & .3 \\
\hline $30-60 \mathrm{~mL} / \mathrm{min} / 1.73 \mathrm{~m}^{2}$ & $15(34.9)$ & $281(30.6)$ & \\
\hline$<30 \mathrm{~mL} / \mathrm{min} / 1.73 \mathrm{~m}^{2}$ & $3(7.0)$ & $28(3.1)$ & \\
\hline \multicolumn{4}{|l|}{ Urine albumin/creatinine, $\mathrm{n}(\%)$} \\
\hline$<10$ & $5(11.6)$ & $331(36.1)$ & .01 \\
\hline $10-30$ & $19(44.2)$ & $266(29.0)$ & \\
\hline $30-300$ & $13(30.2)$ & $254(27.7)$ & \\
\hline$>300$ & $5(11.6)$ & $56(6.1)$ & \\
\hline Nonelective surgery, $\mathrm{n}(\%)$ & $8(18.6)$ & $179(19.5)$ & .9 \\
\hline \multicolumn{4}{|l|}{ Surgery, n (\%) } \\
\hline Isolated $\mathrm{CABG}$ or valve & $15(34.9)$ & $193(21.0)$ & .1 \\
\hline $\mathrm{CABG}+$ valve & $28(65.1)$ & $724(78.0)$ & \\
\hline Off-pump surgery, n (\%) & $3(7.0)$ & $84(9.2)$ & .5 \\
\hline Re-do surgery, n (\%) & $0(0.0)$ & $18(2)$ & .4 \\
\hline CPB time (min), mean (SD) & $138(56)$ & $111(58)$ & .004 \\
\hline $\begin{array}{l}\text { Crossclamp time (min), mean } \\
\text { (SD) }\end{array}$ & $99(46)$ & $76(44)$ & $<.001$ \\
\hline
\end{tabular}

$\overline{S D \text {, Standard deviation; } L V E F \text {, left ventricular ejection fraction; } e G F R \text {, estimated }}$ glomerular filtration rate; $C A B G$, Coronary artery bypass grafting; $C P B$, cardiopulmonary bypass.
APPENDIX E2. Postoperative complications during hospitalization for cardiac surgery by 1-year mortality

\begin{tabular}{|c|c|c|c|}
\hline Complications & Dead at $1 \mathrm{y}$ & Alive at $1 \mathrm{y}$ & $P$ value \\
\hline \multicolumn{4}{|l|}{ Clinical AKI, n (\%) } \\
\hline $\begin{array}{c}\text { Increase }>50 \% \text { or } \\
>0.3 \mathrm{mg} / \mathrm{dL}\end{array}$ & $20(46.5)$ & $310(33.8)$ & .09 \\
\hline Acute dialysis & $2(4.7)$ & $7(0.8)$ & .01 \\
\hline \multicolumn{4}{|l|}{ Nonrenal complications, $\mathrm{n}(\%)$} \\
\hline None & $20(46.5)$ & $571(62.3)$ & .02 \\
\hline 1 or 2 & $15(34.9)$ & $274(29.9)$ & \\
\hline$>2$ & $8(18.6)$ & $72(7.9)$ & \\
\hline $\begin{array}{l}\text { Oliguria on postoperative day } \\
1, \mathrm{n}(\%)\end{array}$ & $0(0.0)$ & $11(1.2)$ & .5 \\
\hline $\begin{array}{l}\text { Mechanical ventilation }>48 \mathrm{~h} \text {, } \\
\mathrm{n}(\%)\end{array}$ & $4(9.3)$ & $30(3.3)$ & .04 \\
\hline $\begin{array}{l}\text { ICU length of stay (d), median } \\
\text { (IQR) }\end{array}$ & $4(2-5)$ & $2(1-3)$ & $<.001$ \\
\hline $\begin{array}{l}\text { Hospital length of stay (d), } \\
\text { median (IQR) }\end{array}$ & $8(6-13)$ & $6(5-8)$ & $<.001$ \\
\hline
\end{tabular}

$A K I$, Acute kidney injury; $I C U$, intensive care unit; $I Q R$, interquartile range. 




A

AKIHZ2 $>=100 \%$ or Dialysis (at any point in time) $\quad 00=1$

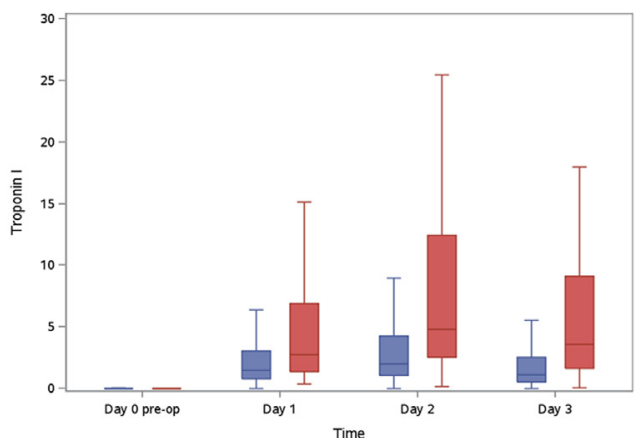

B AKI\#2d $>=100 \%$ or Dialysis (at any point in time) $\quad 0 \quad 01$
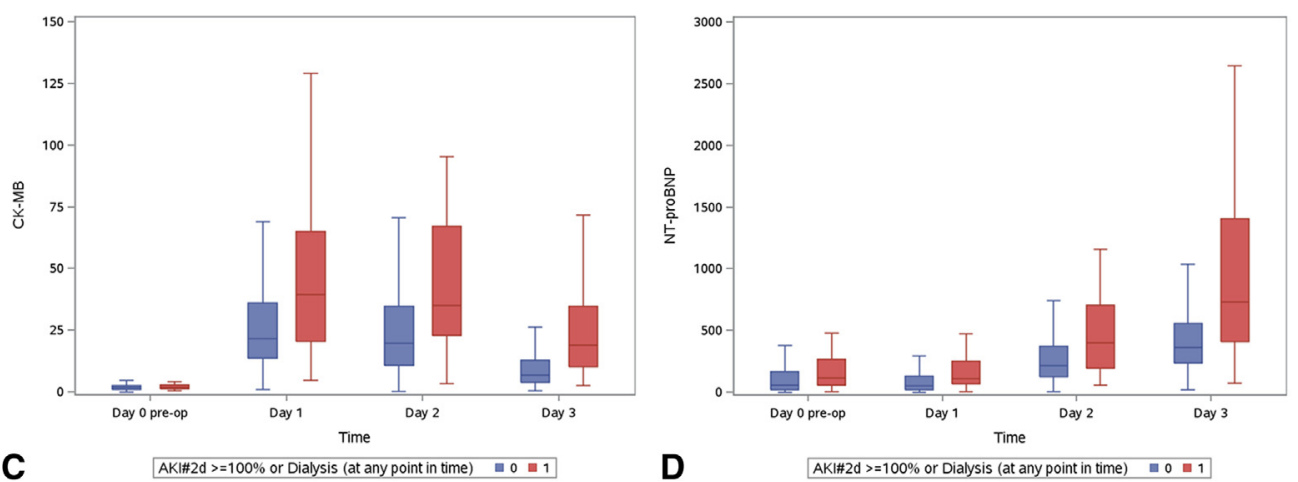

D

AKKitz2d $>=100 \%$ or Dialysis (at any point in time) $\quad=0 \quad 01$

APPENDIX E3. Boxplots of the perioperative cardiac biomarkers according to severe acute kidney injury. A, hs-cTnT. B, cTnI. C, CK-MB. D, NTproBNP. The patients who developed the events are represented in red. The patients free of events are in blue. Day 1 samples were collected within 6 hours of surgery. Horizontal line is the median, and box extends from the 25th to 75th percentile. AKI, Acute kidney injury; $C K-M B$, creatine kinase-MB; $N T$ proBNP, N-terminal prohormone of brain natriuretic peptide.

APPENDIX E4. Biomarkers as predictors of severe acute kidney injury divided by tertiles

\begin{tabular}{|c|c|c|c|c|c|}
\hline & Time point & Tertile & Range & Adjusted OR* $(95 \%$ CI $)$ & $P$ value \\
\hline \multirow{6}{*}{ hs-cTnT (ng/L) } & Preoperative & $\mathrm{T} 1$ & $3.0-7.9$ & 1.0 & \\
\hline & & $\mathrm{T} 2$ & $8-19.3$ & $0.93(0.36-2.41)$ & .9 \\
\hline & & $\mathrm{T} 3$ & $>19.4$ & $1.54(0.60-3.99)$ & .4 \\
\hline & Day 1 & $\mathrm{~T} 1$ & $8.0-291.0$ & 1.0 & \\
\hline & & $\mathrm{T} 2$ & $291.1-588.0$ & $1.67(0.51-5.45)$ & .4 \\
\hline & & $\mathrm{T} 3$ & $>591.0$ & $4.57(1.46-14.36)$ & .009 \\
\hline \multirow[t]{6}{*}{ NT-proBNP (ng/L) } & Preoperative & $\mathrm{T} 1$ & $6.77-287.5$ & 1.0 & \\
\hline & & $\mathrm{T} 2$ & 288.4-1006.4 & $4.13(1.30-13.06)$ & .02 \\
\hline & & $\mathrm{T} 3$ & $>1007.2$ & $4.48(1.33-15.07)$ & .02 \\
\hline & Day 1 & $\mathrm{~T} 1$ & $15.2-264.7$ & 1.0 & \\
\hline & & $\mathrm{T} 2$ & $265.6-827.9$ & $2.52(0.77-8.28)$ & .1 \\
\hline & & $\mathrm{T} 3$ & $\geq 828.8$ & $4.02(1.21-13.38)$ & .02 \\
\hline
\end{tabular}

$O R$, Odds ratio; $C I$, confidence interval; $h s-c T n T$, high-sensitivity cardiac troponin T; $N T$-proBNP, N-terminal prohormone of brain natriuretic peptide. *Adjusted for age (per year), sex, white race, nonelective surgery, diabetes, hypertension, center, congestive heart failure, myocardial infarction, preoperative urine albumin to creatinine ratio, and type of surgery.

APPENDIX E5. Association between biomarkers and severe acute kidney injury

\begin{tabular}{llllrrr}
\hline \multicolumn{1}{c}{ Biomarkers } & Time point & n & AUC (SE) & Cut-point & Sensitivity & Specificity \\
\hline hs-cTnT $(\mathrm{ng} / \mathrm{L})$ & Day 1 & 949 & $0.68(0.05)$ & 714.4 & 0.59 & 0.8 \\
cTnI $(\mu \mathrm{g} / \mathrm{L})$ & Day 1 & 959 & $0.65(0.05)$ & 1.8 & 0.70 & 0.6 \\
CK-MB $(\mu \mathrm{g} / \mathrm{L})$ & Preoperative & 958 & $0.57(0.05)$ & 1.9 & 0.59 & 0.5 \\
& Day 1 & 959 & $0.67(0.05)$ & 39.5 & 0.51 & 0.78 \\
NT-proBNP $(\mathrm{ng} / \mathrm{L})$ & Preoperative & 931 & $0.64(0.04)$ & 504.0 & 0.5 \\
& Day 1 & 947 & $0.68(0.04)$ & 556.5 & 0.81 \\
\hline
\end{tabular}

$A U C$, Area under the curve; $S E$, standard error; $h s-c T n T$, high-sensitivity cardiac troponin T; $c T n I$, cardiac troponin I; $C K-M B$, creatine kinase-MB; $N T$-proBNP, N-terminal prohormone of brain natriuretic peptide. 
APPENDIX E6. Biomarkers as predictors of 1-year mortality divided by tertiles

\begin{tabular}{|c|c|c|c|c|c|}
\hline & Time point & Tertile & Range & OR* $(95 \%$ CI $)$ & $P$ value \\
\hline \multirow{9}{*}{ hs-cTnT (ng/L) } & Preoperative & $\mathrm{T} 1$ & $3.0-7.9$ & 1.0 & \\
\hline & & $\mathrm{T} 2$ & $8.0-19.3$ & $3.78(1.21-11.77)$ & .02 \\
\hline & & $\mathrm{T} 3$ & $>19.4$ & $4.18(1.27-13.74)$ & .02 \\
\hline & Day 1 & $\mathrm{~T} 1$ & $8.0-290.8$ & 1.0 & \\
\hline & & $\mathrm{T} 2$ & 291.1-587.8 & $1.04(0.40-2.68)$ & .9 \\
\hline & & $\mathrm{T} 3$ & $\geq 591.4$ & $1.66(0.62-4.42)$ & .3 \\
\hline & Highest measured & $\mathrm{T} 1$ & $9.1-393.7$ & 1.0 & \\
\hline & & $\mathrm{T} 2$ & $393.9-802.6$ & $2.23(0.76-6.52)$ & .1 \\
\hline & & $\mathrm{T} 3$ & $>804$ & $2.95(0.96-9.06)$ & .1 \\
\hline \multirow[t]{9}{*}{ NT-proBNP (ng/L) } & Preoperative & $\mathrm{T} 1$ & $6.8-287.5$ & 1.0 & \\
\hline & & $\mathrm{T} 2$ & 288.4-1006.4 & $15.24(1.95-118.91)$ & .009 \\
\hline & & $\mathrm{T} 3$ & $\geq 1009.8$ & $27.20(3.46-213.50)$ & .002 \\
\hline & Day 1 & $\mathrm{~T} 1$ & $15.2-264.7$ & 1.0 & \\
\hline & & $\mathrm{T} 2$ & $265.6-827.9$ & $15.10(1.93-117.94)$ & .01 \\
\hline & & $\mathrm{T} 3$ & $\geq 828.8$ & $25.74(3.29-201.18)$ & .002 \\
\hline & Highest measured & $\mathrm{T} 1$ & $70.2-2462.7$ & 1.0 & \\
\hline & & $\mathrm{T} 2$ & $2468.6-4260.6$ & $9.83(2.18-44.24)$ & .003 \\
\hline & & $\mathrm{T} 3$ & $\geq 8263.2$ & $11.68(2.50-54.55)$ & .002 \\
\hline
\end{tabular}

For day 1 and highest measured biomarkers: adjusted for age (per year), sex, white race, nonelective surgery, diabetes, hypertension, center, congestive heart failure, myocardial infarction, preoperative urine albumin to creatinine ratio, and type of surgery and change in serum creatinine day 10 to 6 hours from preoperatively. $O R$, Odds ratio; $C I$, confidence interval; $h s-c T n T$, high-sensitivity cardiac troponin $\mathrm{T} ; N T$-proBNP, N-terminal prohormone of brain natriuretic peptide. *For preoperative biomarkers: adjusted for age (per year), sex, white race, nonelective surgery, diabetes, hypertension, center, congestive heart failure, myocardial infarction, preoperative urine albumin to creatinine ratio, and type of surgery.

APPENDIX E7. Association between biomarkers and 1-year mortality

\begin{tabular}{|c|c|c|c|c|c|c|}
\hline & Time point & $\mathbf{n}$ & AUC (SE) & Cut-point & Sensitivity & Specificity \\
\hline \multirow[t]{3}{*}{ hs-cTnT (ng/L) } & Preoperative & 928 & $0.64(0.04)$ & 9.0 & 0.88 & 0.39 \\
\hline & Day 1 & 949 & $0.59(0.05)$ & 912.6 & 0.38 & 0.82 \\
\hline & Highest measured & 952 & $0.64(0.04)$ & 542.9 & 0.74 & 0.51 \\
\hline \multirow[t]{3}{*}{$\mathrm{cTnI}(\mu \mathrm{g} / \mathrm{L})$} & Preoperative & 956 & $0.59(0.04)$ & $<0.01$ & 0.64 & 0.53 \\
\hline & Day 1 & 959 & $0.59(0.05)$ & 5.0 & 0.35 & 0.85 \\
\hline & Highest measured & 959 & $0.63(0.04)$ & 4.9 & 0.49 & 0.74 \\
\hline \multirow[t]{2}{*}{ CK-MB $(\mu \mathrm{g} / \mathrm{L})$} & Preoperative & 958 & $0.51(0.04)$ & 3.2 & 0.98 & 0.17 \\
\hline & Day 1 & 959 & $0.55(0.05)$ & 38.3 & 0.40 & 0.77 \\
\hline \multirow[t]{3}{*}{ NT-proBNP (ng/L) } & Preoperative & 931 & $0.72(0.03)$ & 843.6 & 0.81 & 0.56 \\
\hline & Day 1 & 947 & $0.71(0.03)$ & 751.8 & 0.71 & 0.64 \\
\hline & Highest measured & 956 & $0.68(0.04)$ & 2940.5 & 0.84 & 0.47 \\
\hline
\end{tabular}

$A U C$, Area under the curve; $S E$, standard error; $h s-c T n T$, high-sensitivity cardiac troponin $\mathrm{T} ; c T n I$, cardiac troponin I; $C K-M B$, creatine kinase-MB; $N T$-proBNP, N-terminal prohormone of brain natriuretic peptide.

APPENDIX E8. Log-transformed biomarkers as predictors of long-term mortality, median follow-up of 3 years

\begin{tabular}{llr}
\hline & Time point & HR* (95\% CI $)$ \\
\hline hs-cTnT & Preoperative & $1.31(1.14-1.51)$ \\
& Day 1 & $1.28(1.03-1.58)$ \\
& Highest measured & $1.25(1.05-1.47)$ \\
cTnI & Preoperative & $1.04(0.9-1.21)$ \\
& Day 1 & $1.14(0.98-1.31)$ \\
& Highest measured & $1.12(0.96-1.32)$ \\
CK-MB & Preoperative & $1.17(1.02-1.33)$ \\
& Day 1 & $1.1(0.91-1.32)$ \\
NT-proBNP & Highest measured & $1.02(0.84-1.23)$ \\
& Preoperative & $1.44(1.30-1.59)$ \\
& Day 1 & $1.37(1.26-1.49)$ \\
& Highest measured & $1.93(1.42-2.62)$ \\
\hline
\end{tabular}

For day 1 and highest measured biomarkers: adjusted for age (per year), sex, white race, nonelective surgery, diabetes, hypertension, center, congestive heart failure, myocardial infarction, preoperative urine albumin to creatinine ratio, and type of surgery and change in serum creatinine day 10 to 6 hours from preoperative. $H R$, Hazard ratio; $C I$, confidence interval; $h s$-cTnT, high-sensitivity cardiac troponin T; $c T n I$, cardiac troponin I; $C K-M B$, creatine kinase-MB; NT-proBNP, N-terminal prohormone of brain natriuretic peptide. *For preoperative biomarkers: adjusted for age (per year), sex, white race, nonelective surgery, diabetes, hypertension, center, congestive heart failure, myocardial infarction, preoperative urine albumin to creatinine ratio, and type of surgery. 

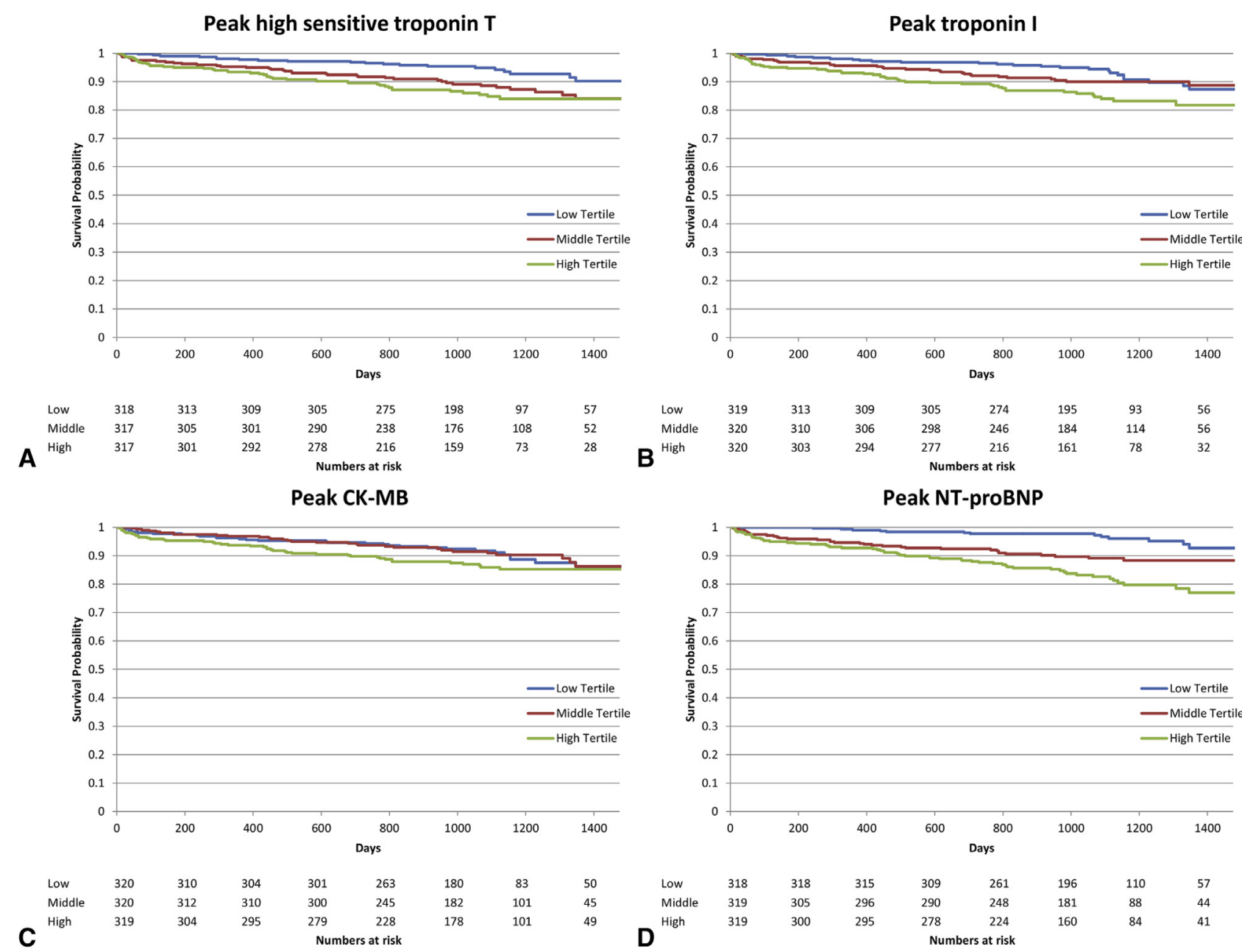

APPENDIX E9. A, Kaplan-Meier curve: association between highest measured high-sensitivity troponin $\mathrm{T}$ tertiles and long-term mortality. B, Kaplan-Meier curve: association between highest measured cardiac troponin I tertiles and long-term mortality. C, Kaplan-Meier curve: association between highest measured creatine kinase-MB tertiles and long-term mortality. D, Kaplan-Meier curve: association between highest measured N-terminal prohormone of brain natriuretic peptide tertiles and long-term mortality. $C K-M B$, Creatine kinase-MB; NT-proBNP, N-terminal prohormone of brain natriuretic peptide. 